\title{
Management of the dead during COVID-19 outbreak in Malaysia
}

\author{
Lay See Khoo ${ }^{1}$ (D) $\cdot$ Ahmad Hafizam Hasmi ${ }^{1}$ - Mohamad Azaini Ibrahim ${ }^{1} \cdot$ Mohd Shah Mahmood $^{1}$
}

Accepted: 25 May 2020 / Published online: 9 June 2020

(C) Springer Science+Business Media, LLC, part of Springer Nature 2020

\begin{abstract}
The emergence of a novel human coronavirus, SARS-CoV-2, causing severe respiratory tract infections in humans, is affecting all countries of the world and has become a global health concern. Since the virus was first identified in December 2019, the number of deaths have been propagating exponentially, causing countries across the world, including Malaysia, to increase emergency measures to combat the virus. Due to the fact that the COVID-19 pandemic does not discriminate its victims, it is of paramount importance to construct a plan for management of the dead for all suspected or confirmed COVID-19 cases, including the unidentified deceased, as an essential portion of the humanitarian forensic action approach. This document provides an overview on ways to maximize the local collective capacity from various government agencies to manage the dead based on the prevailing regulations and legislation in the country, in preparation for possible large scale deaths from this pandemic. The National Institute of Forensic Medicine Malaysia has improvised procedures and guidelines for management of the dead within the existing regulations in order to achieve a balance between medicolegal requirements and the safety of personnel managing the bodies of the deceased with suspected or confirmed COVID-19 infection; at the site of death, during transport, during postmortem procedures, storage and preparation before and during burial or cremation as well as environmental cleaning and disinfection, involving various agencies in the country. A form of temporary controlled burial is as an option to allow the reinvestigation of a decedent to help formally identify victims of the pandemic such as undocumented migrants or refugees who were previously not identified. Due to the different legal requirements and mortality rates between countries, there is no one-size-fits-all approach to the management of the dead. Whenever possible, every opportunity and assistance must be given to families to mourn their loved ones, even in times of crisis or an outbreak, in order to sustain an appropriate level of dignity and respect.
\end{abstract}

Keywords COVID-19 $\cdot$ Management of the dead $\cdot$ Humanitarian forensic action $\cdot$ Pandemic

\section{Background}

A cluster of 27 cases of pneumonia of unknown aetiology was reported by the Chinese health authorities in Wuhan, Hubei Province, China on 31st December 2019, and subsequently the China Centre for Disease Control and Prevention (CDC) reported a novel coronavirus as the causative agent of this outbreak on 9th January 2020 [1, 2]. The virus is phylogenetically in the SARS-CoV clade and is called 'Severe Acute Respiratory Syndrome Coronavirus-2' (SARS-CoV-2). The disease associated with the virus is referred to as Coronavirus Disease 2019 (COVID-19). The pathobiology of COVID-19 remains

Lay See Khoo

khoolaysee@yahoo.com

1 National Institute of Forensic Medicine (IPFN), Hospital Kuala Lumpur, Jalan Pahang, 50586 Kuala Lumpur, Malaysia incompletely understood and significant efforts are underway to study it worldwide [3]. Current understanding about how the virus that causes COVID-19 spreads is largely based on what is known about similar coronaviruses. Together with Severe Acute Respiratory Syndrome (SARS) coronavirus and Middle East Respiratory Syndrome (MERS) coronavirus, the SARS$\mathrm{CoV}-2$ is the third highly pathogenic human coronavirus that has emerged in the last two decades [4] and are all categorized and considered hazard group 3 (HG3) pathogens [3, 5]. As of the 5th April 2020, COVID-19 has affected 180 countries with a total death toll of 67,594 cases worldwide [6].

\section{Introduction}

Since the initial identification of the virus in China, global spread has been rapid and subsequently, WHO announced the COVID-19 outbreak a pandemic on the 12th March 2020 [7]. 
In view of this, the world faces a severe and acute public health emergency. While SARS-CoV-2 continues to spread, the number of deaths continue to increase globally. COVID-19 is transmitted via droplets and fomites during close unprotected contact between an infector and infectee [8]. Airborne spread has not been reported for COVID-19 yet, however, it can be envisaged if certain aerosol-generating procedures are conducted in health care facilities, including mortuaries during autopsies [8].

To date, there are about 102 deaths of confirmed COVID19 cases in Malaysia as of the end of April 2020 [9]. The first death was reported on 17 March 2020 in Johor and was from a cluster of cases thought to be initiated by the gathering of a large group of people for religious purposes. As shown in the distribution of COVID-19 deaths in Malaysia (Table 1), deaths due to COVID-19 occur in the older members of the population with co-morbidities such as hypertension, diabetes, stroke, chronic diseases and heart related problems. From the data, it is documented that COVID-19 deaths are concentrated in cities like Kuala Lumpur, Johor and Selangor in Peninsular Malaysia as well as Sarawak in East Malaysia (Table 2).

Although the number of deaths reported in the country is not increasing in a hyperbolic curve pattern, there is a dire and urgent need to be well prepared to manage the dead from this outbreak. This is important not only for the healthcare workers but also for the first responders in particular. This document aims to provide an overview on ways to augment the local collective capacity to manage the deceased when our normal capacity and capability in managing the dead could be overwhelmed, based on the prevailing regulations and legislation in the country. There is a need to improvise procedures and guidelines for management of the dead within the existing regulations in order to find a balance between medicolegal requirements and the safety of the personnel managing the bodies of the deceased with suspected or confirmed COVID19 infection; at the site of death, during transport, during postmortem procedures, storage and preparation of the body before and during burial or cremation as well as environmental cleaning and disinfection, involving various agencies in the country.

\section{Preparedness phase}

The mode of transmission of the virus is thought to be largely by inhalation of respiratory droplets although acquisition via the skin surface is another possibility [3]. Based on current evidence, the COVID-19 virus is transmitted between people through droplets, fomites and close contact, with possible spread through faces [7]. Estimation of mortality and healthcare demand based on data from China have given rise to the urgent need for the Ministry of Health Malaysia to take prompt early public health measures and interventions. At the same time, responding to the increasing number of COVID-19 cases in the beginning of February of this year, the National Institute of Forensic Medicine (IPFN) Malaysia has also taken the initiative to prepare for the management of the dead for all COVID-19 suspected or confirmed cases.

\section{Guidelines}

Immediately after the outbreak in Wuhan, China began to spread, many organizations and institutions around the world started to release guidance on considerations related to the safe handling of bodies of deceased persons with suspected or confirmed COVID-19 infection. Among these are guidelines by the European Centre for Disease Prevention and Control [2], guidance on postmortem examinations for mortuary workers in suspected COVID-19 cases by the Royal College of Pathologists (RCPath) [3], technical recommendations for healthcare and deathcare workers by the International Committee of the Red Cross (ICRC) [5], interim guidance on the infection prevention and control for the safe management of a dead body in the context of COVID-19 by the World Health Organization [7] and many others. Similarly, the National Institute of Forensic Medicine (IPFN) Malaysia has also produced a guideline on management of the dead for all COVID-19 suspected or confirmed deaths within the hospital as well as from outside the hospital (brought-in-dead cases by police). This guideline consists of various sections including guidelines on body transport from Emergency Departments or wards to the mortuary, postmortem examination, handling of the body and religious/ritual body preparation and disposal.

\section{Training}

To strengthen the principles of management of the dead from this outbreak, sufficient training must be provided not only for the healthcare workers, but also to the first responders who are also at risk when managing the dead. In this preparation phase, the IPFN Malaysia has taken the initiative to engage the Royal Malaysia Police (RMP) to create awareness on the risk of COVID-19 infection and safety precautions that must be adhered prevent infection to all RMP ground officers during the investigation of a body found at the scene. Training sessions were also given to the RMP on proper hand hygiene and washing, donning and doffing of the standard full personal protective equipment (PPE) which consists of a surgical mask, double surgical gloves, face shield, impervious gown or apron with full sleeve coverage, shoe covers and surgical cap [10]. Concurrently, personnel working in the mortuary are given refresher hands-on and practical training on the use of the powered air-purifying respirator (PAPR) as well as donning and doffing of the standard full PPE in all forensic medicine centers in the country. Deployment of resources and personnel to fully utilize and maximize local capacity are put in plans at 
Table 1 Distribution of COVID-19 death cases in Malaysia

\begin{tabular}{|c|c|c|c|c|}
\hline Case & Age (year) & Date & State & History \\
\hline$\# 1$ & 34 & $17 \mathrm{Mac}$ & Johor & Religion gathering cluster \\
\hline \#2 & 60 & $17 \mathrm{Mac}$ & Sarawak & Religion gathering cluster \\
\hline \#3 & 58 & $21 \mathrm{Mac}$ & Sabah & Religion gathering cluster \\
\hline \#4 & 50 & $21 \mathrm{Mac}$ & Melaka & Religion gathering cluster \\
\hline$\# 5$ & 79 & $22 \mathrm{Mac}$ & Sarawak & Close contact \\
\hline \#6 & 40 & $22 \mathrm{Mac}$ & Sarawak & Close contact \\
\hline \#7 & 57 & $22 \mathrm{Mac}$ & Wilayah Persekutuan Kuala Lumpur & Religion gathering cluster \\
\hline \#8 & 69 & $22 \mathrm{Mac}$ & Kelantan & Religion gathering cluster \\
\hline \#9 & 48 & $22 \mathrm{Mac}$ & Perlis & History of travel to Turkey \\
\hline$\# 10$ & 74 & $22 \mathrm{Mac}$ & Penang & Religion gathering cluster \\
\hline \#11 & 70 & $23 \mathrm{Mac}$ & Wilayah Persekutuan Kuala Lumpur & History of travel \\
\hline$\# 12$ & 70 & $23 \mathrm{Mac}$ & Johor & Religion gathering cluster \\
\hline \#13 & 49 & $23 \mathrm{Mac}$ & Sarawak & Close contact \\
\hline \#14 & 51 & $23 \mathrm{Mac}$ & Sarawak & Close contact \\
\hline \#15 & 70 & $24 \mathrm{Mac}$ & Johor & Hypertension, Diabetes \\
\hline \#16 & 75 & $25 \mathrm{Mac}$ & Wilayah Persekutuan Kuala Lumpur & Chronic disease \\
\hline$\# 17$ & 66 & $25 \mathrm{Mac}$ & Johor & Chronic disease \\
\hline \#18 & 56 & $25 \mathrm{Mac}$ & Johor & Chronic disease \\
\hline \#19 & 68 & $25 \mathrm{Mac}$ & Johor & Severe Acute Respiratory Infection (SARI) \\
\hline \#20 & 76 & $26 \mathrm{Mac}$ & Kelantan & Religion gathering cluster \\
\hline \#21 & 63 & $26 \mathrm{Mac}$ & Kedah & Religion gathering cluster \\
\hline$\# 22$ & 48 & $26 \mathrm{Mac}$ & Johor & Religion gathering cluster \\
\hline$\# 23$ & 62 & $26 \mathrm{Mac}$ & Perak & Chronic disease \\
\hline \#24 & 35 & $27 \mathrm{Mac}$ & Wilayah Persekutuan Kuala Lumpur & History of travel to Indonesia \\
\hline \#25 & 83 & $27 \mathrm{Mac}$ & Perak & Chronic disease \\
\hline \#26 & 53 & $27 \mathrm{Mac}$ & Selangor & Close contact \\
\hline \#27 & 61 & $28 \mathrm{Mac}$ & Johor & Hypertension, Diabetes \\
\hline \#28 & 91 & $29 \mathrm{Mac}$ & Selangor & Hypertension, Diabetes, Kidney Disease \\
\hline$\# 29$ & 64 & $29 \mathrm{Mac}$ & Negeri Sembilan & Hypertension, Diabetes \\
\hline$\# 30$ & 76 & $29 \mathrm{Mac}$ & Selangor & Hypertension, Diabetes, Kidney Disease \\
\hline \#31 & 27 & $29 \mathrm{Mac}$ & Perak & Hypertension, Diabetes, Kidney Disease \\
\hline \#32 & 50 & $29 \mathrm{Mac}$ & Johor & Hypertension \\
\hline \#33 & 37 & $29 \mathrm{Mac}$ & Johor & History of travel to India \\
\hline \#34 & 77 & $29 \mathrm{Mac}$ & Wilayah Persekutuan Kuala Lumpur & Hypertension \\
\hline \#35 & 57 & $30 \mathrm{Mac}$ & Selangor & History of travel to Indonesia \\
\hline \#36 & 47 & $30 \mathrm{Mac}$ & Sarawak & Severe Acute Respiratory Infection (SARI) \\
\hline \#37 & 46 & $30 \mathrm{Mac}$ & Sarawak & Hypertension, Autoimmune Disease \\
\hline \#38 & 48 & $31 \mathrm{Mac}$ & Negeri Sembilan & Hypertension \\
\hline \#39 & 69 & $31 \mathrm{Mac}$ & Wilayah Persekutuan Kuala Lumpur & Hypertension, Diabetes \\
\hline \#40 & 69 & $31 \mathrm{Mac}$ & Johor & Hypertension, Diabetes \\
\hline \#41 & 40 & $31 \mathrm{Mac}$ & Sarawak & Severe Acute Respiratory Infection (SARI) \\
\hline \#42 & 81 & $31 \mathrm{Mac}$ & Selangor & Heart Disease \\
\hline \#43 & 73 & $31 \mathrm{Mac}$ & Selangor & Diabetes, Heart Disease \\
\hline \#44 & 80 & 1 April & Wilayah Persekutuan Kuala Lumpur & Hypertension, Diabetes, Heart Disease \\
\hline \#45 & 42 & 1 April & Wilayah Persekutuan Kuala Lumpur & Hypertension, Diabetes \\
\hline \#46 & 37 & 2 April & Johor & Chronic disease, Autoimmune Disease \\
\hline \#47 & 78 & 2 April & Johor & Hypertension, Gout \\
\hline \#48 & 85 & 2 April & Johor & Hypertension, Diabetes, Heart Disease \\
\hline \#49 & 61 & 2 April & Sarawak & Close contact \\
\hline \#50 & 69 & 2 April & Negeri Sembilan & Close contact \\
\hline \#51 & 84 & 3 April & Wilayah Persekutuan Kuala Lumpur & Heart Disease \\
\hline \#52 & 52 & 3 April & Negeri Sembilan & Severe Acute Respiratory Infection (SARI) \\
\hline$\# 53$ & 73 & 3 April & Perak & Hypertension, Diabetes, Heart Disease, Kidney Disease \\
\hline$\# 54$ & 85 & 4 April & Wilayah Persekutuan Kuala Lumpur & Heart Disease \\
\hline \#55 & 66 & 4 April & Kelantan & Hypertension \\
\hline$\# 56$ & 56 & 4 April & Sarawak & Heart Disease \\
\hline \#57 & 61 & 4 April & Pahang & Diabetes \\
\hline \#58 & 72 & 5 April & Sarawak & Hypertension, Diabetes \\
\hline \#59 & 68 & 5 April & Wilayah Persekutuan Kuala Lumpur & Diabetes \\
\hline$\# 60$ & 53 & 5 April & Sarawak & Severe Acute Respiratory Infection (SARI) \\
\hline$\# 61$ & 66 & 5 April & Sabah & Hypertension, Diabetes, Kidney Disease \\
\hline$\# 62$ & 67 & 6 April & Terengganu & Hypertension, Diabetes \\
\hline$\# 63$ & 71 & 7 April & Johor & History of travel to Indonesia \\
\hline \#64 & 58 & 8 April & Negeri Sembilan & Hypertension, Diabetes \\
\hline$\# 65$ & 69 & 8 April & Wilayah Persekutuan Kuala Lumpur & Diabetes \\
\hline
\end{tabular}


Table 1 (continued)

\begin{tabular}{|c|c|c|c|c|}
\hline Case & Age (year) & Date & State & History \\
\hline \#66 & 59 & 9 April & Melaka & Chronic disease, Autoimmune Disease \\
\hline$\# 67$ & 23 & 9 April & Sarawak & Thyroid Disease \\
\hline \#68 & 62 & 10 April & Sabah & Diabetes \\
\hline$\# 69$ & 77 & 10 April & Wilayah Persekutuan Kuala Lumpur & Diabetes \\
\hline$\# 70$ & 88 & 10 April & Selangor & Hypertension, Diabetes, Dementia \\
\hline \#71 & 66 & 11 April & Negeri Sembilan & Hypertension, Diabetes, Gout \\
\hline \#72 & 71 & 11 April & Selangor & Hypertension, Diabetes, Heart Disease \\
\hline \#73 & 63 & 11 April & Perak & Hypertension \\
\hline$\# 74$ & 54 & 12 April & Negeri Sembilan & Hypertension, Diabetes, Kidney Disease \\
\hline \#75 & 90 & 12 April & Perak & Hypertension, Diabetes, Heart Disease \\
\hline \#76 & 47 & 12 April & Sarawak & Hypertension \\
\hline \#77 & 60 & 13 April & Melaka & Hypertension, Heart \& Kidney Disease \\
\hline \#78 & Unknown & 14 April & Sabah & Unknown \\
\hline \#79 & 65 & 14 April & Selangor & Hypertension, Diabetes, Kidney Disease \\
\hline \#80 & 63 & 14 April & Wilayah Persekutuan Kuala Lumpur & Heart \& Kidney Disease \\
\hline \#81 & 74 & 14 April & Melaka & Kidney Disease \\
\hline \#82 & 81 & 14 April & Johor & Diabetes \\
\hline$\# 83$ & 69 & 15 April & Selangor & Hypertension, Diabetes \\
\hline \#84 & 66 & 16 April & Wilayah Persekutuan Kuala Lumpur & Hypertension, Heart Disease \\
\hline \#85 & 85 & 17 April & Pahang & Close Contact \\
\hline \#86 & 85 & 17 April & Selangor & Hypertension, Stroke \\
\hline \#87 & 60 & 18 April & Wilayah Persekutuan Kuala Lumpur & Hypertension, Diabetes \\
\hline \#88 & 36 & 18 April & Selangor & Severe Acute Respiratory Infection (SARI) \\
\hline \#89 & 51 & 19 April & Johor & Hypertension, Diabetes, Heart Disease, Kidney Disease \\
\hline \#90 & 72 & 22 April & Selangor & Hypertension, Diabetes \\
\hline \#91 & 69 & 22 April & Sarawak & Hypertension, Diabetes, Kidney Disease \\
\hline \#92 & 92 & 22 April & Wilayah Persekutuan Kuala Lumpur & Hypertension, Diabetes, Dementia \\
\hline \#93 & 72 & 22 April & Selangor & Hypertension, Cancer \\
\hline \#94 & 32 & 23 April & Johor & Hypertension \\
\hline \#95 & 67 & 23 April & Pahang & Hypertension, Diabetes, Heart Disease, Kidney Disease \\
\hline \#96 & 61 & 24 April & Selangor & Hypertension, Diabetes, Kidney Disease \\
\hline \#97 & 62 & 25 April & Selangor & Heart Disease \\
\hline \#98 & 62 & 25 April & Wilayah Persekutuan Kuala Lumpur & Hypertension \\
\hline \#99 & 78 & 27 April & Johor & Hypertension, Diabetes, Stroke \\
\hline$\# 100$ & 67 & 28 April & Selangor & Hypertension, Diabetes \\
\hline$\# 101$ & 64 & 30 April & Pahang & Cancer \\
\hline$\# 102$ & 72 & 30 April & Sarawak & Hypertension \\
\hline
\end{tabular}

this level. Hospitals and local agencies also worked closely to coordinate this training activities.

\section{Death investigation under the Criminal Procedure Code (CPC)}

In Malaysia, the leading agency in an inquiry into death is the RMP. Section 329 of the Criminal Procedure Code (CPC) specifies the police are bound by law to investigate all sudden death reports including homicide, suicide and accidental deaths [11]. The police then arrange for a postmortem examination to be conducted as stipulated in Section 330 of the same code. Similarly, under the same Act, Section 331 states that the mandate to conduct a postmortem examination of a body is given to a Government Medical Officer, which includes a forensic pathologist [11].

The police, as first responders to a scene of incident, will invariably come in close contact with the dead. Due to the fact that COVID-19 virus carriers can be asymptomatic, the police or emergency responders are particularly vulnerable to infection. Hence, the role of the Public Health Officers under the provision of the Prevention and Control of Infectious Diseases Act 1988 will be to assist the police at the scene for all suspected or confirmed COVID-19 cases before transporting the deceased body to mortuary.

\section{Death investigation under the Prevention and Control of Infectious Diseases Act 1988}

As COVID-19 cases increase by multiplies affecting populations in large areas in the country and in conjunction with disease spread being declared a pandemic by World Health Organization (WHO), Malaysia enforced its Prevention and Control of Infectious Diseases Act 1988. As part of the measures to curb the spread of the disease, the Prime Minister of Malaysia announced the implementation of the Movement 
Table 2 Summary of COVID-19 cases in Malaysia according to States as of 30 April 2020

\begin{tabular}{lcc}
\hline State & $\begin{array}{c}\text { Cumulative } \\
\text { positive cases }\end{array}$ & $\begin{array}{l}\text { Total } \\
\text { death cases }\end{array}$ \\
\hline Perlis & 18 & 1 \\
Kedah & 95 & 1 \\
Penang & 121 & 1 \\
Perak & 253 & 6 \\
Selangor & 1431 & 16 \\
Negeri Sembilan & 513 & 7 \\
Melaka & 198 & 4 \\
Johor & 663 & 19 \\
Pahang & 294 & 4 \\
Terengganu & 110 & 1 \\
Kelantan & 155 & 3 \\
Sabah & 315 & 4 \\
Sarawak & 507 & 17 \\
Wilayah Persekutuan Kuala Lumpur & 1232 & 18 \\
Wilayah Persekutuan Putrajaya & 81 & 0 \\
Wilayah Persekutuan Labuan & 16 & 0 \\
TOTAL & 6002 & 102 \\
\hline
\end{tabular}

Control Order (MCO) throughout the country on 18th March 2020. Under Section 16 and 17 of the Prevention and Control of Infectious Diseases Act 1988, the investigation of a death related to an infectious disease falls under the jurisdiction of a Public Health Officer, including the recommendation of examination of the dead $[12,13]$.

\section{Deaths outside of hospital}

The Public Health Officer at the scene of incident, after being notified of a suspected or confirmed COVID-19 body, supervises and guides the police officers at the scene on proper donning and doffing of the standard full PPE before attending to the deceased body. The body is wrapped in three layers. First the body is wrapped in a layer of white cotton linen, the body is then placed in a cadaver body bag. The body with its two layers is then put in another cadaver body bag (the third layer) and the outer surface is disinfected with $0.5 \%$ sodium hypochlorite. Subsequent to the transportation of the body to the mortuary, area decontamination of the scene as well as the hearse is performed by the Public Health Officer.

\section{Postmortem examination}

Postmortem examinations are performed in the Bio-Safety Level 3 (BSL-3) autopsy suite in the IPFN, adhering strictly to the protocols and precautions on the use of recommended full PPE with PAPR as stated in the guidelines for handling infectious disease cases, including sample collection. After examination, the body is then wrapped in three layers (as described above) to prepare for disposal.

\section{Disposal}

Preparation of the body and its release to the next-of-kin is conducted under the supervision of the Public Health Officer. Claimants or next-of-kin are prohibited from performing normal religious or ritual practices including opening the sealed coffin or touching the body. The only allowable religious or ritual practices are the funeral prayer for non-Muslims and tayammum (dry purification) for Muslims, performed on the outer body bag layer by the Islamic authorities under the supervision of the health authorities. All probable or confirmed COVID-19 positive bodies are not allowed to be embalmed and it is recommended they are taken for burial or cremation directly from the mortuary, preferably within the same day of the postmortem examination. The family of deceased individuals are able to accept the limitations due to the current pandemic.

\section{Management of the dead (large scale) under the purview of Malaysia National Security Council (MNSC) directive 20}

A severe pandemic is the incident most likely to create a need for an excessive death number contingency planning. During a pandemic, there is potential for a significant increase in the number of deaths in a relatively short period of time, placing pressure on local service providers with responsibilities relating to managing the deceased [14]. For this reason, a contingency plan for surge capacity to manage excess deaths in a pandemic needs to be put in place. When the situation has transitioned into the mitigation phase, whereby the containment of the virus in the community has failed and the increase of the death rate has gone beyond the local forensic capacity, the Directive 20 is activated under the command of the National Disaster Management Agency (NADMA).

Directive 20 is a government issued directive that includes policy and mechanisms to provide direction in relation to national natural disaster and relief management, including the outbreak of disease [15]. The main purpose of the Directive is to put in place a comprehensive emergency management program which seeks to mitigate the effect of various hazards, to prepare measures which will preserve life and minimize damage to the environment, or respond during emergencies and provide assistance, and to establish a recovery system to ensure the affected community to return to normalcy [15].

When there are large scale deaths the emergency management capability will comprise the first responders as stipulated in the Directive 20, namely the Royal Malaysia Police (RMP), 
Malaysia Civil Defence Forces (APM) and the Malaysia Armed Forces (ATM). The NADMA oversees the whole operation, and the coordination of the above mentioned first responders' agencies as well as the distribution of any financial assistance, equipment, transport, or PPE requirements. They also manage any temporary field mortuaries, cold body storage, manpower, religious burials or cremations. The implementation of the protocols and the measures to address these issues were a smooth transition administered by NADMA and IPFN Malaysia under the purview of the Directive 20. IPFN Malaysia has provided input to assist with the management of the dead for the national emergency. All first responders are given training on safety precautions and the risk of COVID-19 infection while managing mass deaths at the scene.

At this time, when mortuaries are overloaded with infectious remains threatening the health of the entire community, examinations will cease for all COVID-19 related deaths. However, there is still a requirement to perform postmortem examinations within the context of legal considerations for homicides and suspicious deaths during a disease pandemic. The management of the dead from COVID-19 should not impede the medicolegal investigation of the death where required by the authorities and legislation but additional health and safety precautions should be adopted for the necessary postmortem procedures.

\section{COVID-19 centralized body facility}

This type of facility, identified by NADMA and situated at various locations, functions as temporary mortuary centre for all COVID-19 deaths in the country. It is a holding area for all the dead whereby its security is maintained by the RMP, APM or ATM and is equipped with cold body storage containers in which bodies are properly tagged, documented and stored. The centre should be big enough to accommodate thousands of bodies as well as be able to function as the administration centre, rest area and accommodation for first responders' personnel working around the clock.

\section{DNA sampling for identification and body preparation}

For unknown bodies, buccal swabs will be taken for DNA profiling to keep as a record for future identification. The body will then be subjected to religious body preparation and last rites. All procedures are done by trained personnel in full PPE.

\section{Disposal/Temporary controlled burial}

Temporary controlled burial is a method for a long-term temporary storage of unidentified bodies. The temperature underground is lower than at the surface, therefore providing natural refrigeration [16]. It is done by performing a burial procedure for all human remains, where each body will clearly be marked with GPS, to facilitate future exhumation in the event of the identification of the next-of-kin [16, 17]. Temporary controlled burial was used as a practical solution to deal with a large number of unidentified decedents, presumed victims of a human trafficking ring along the Malaysia-Thai border, in 2015, when authorities exhumed one hundred and sixty three unidentified bodies from clandestine graves [17]. Temporary controlled burial provides a fundamental solution for unidentified victims to be treated with dignity and respect as well as an opportunity to be identified in future.

\section{Discussion}

There remain large uncertainties in the underlying determinants of the severity of COVID-19 infection and how these translate across settings. However, clear risk factors include age, with older people more likely to require hospitalization and to subsequently die as a result of infection, and underlying co-morbidities including hypertension, diabetes and coronary heart disease serving to exacerbate symptoms [4]. Variation in these factors between countries, namely the economic status, age-specific contact patterns and social mixing will have material consequences for transmission of SARS-CoV-2. Due to the different legal requirements and mortality rate between countries, there is no one-size-fits-all approach on the management of the dead. The essential ways to react to such situations are rapid decision making by the relevant higher authorities and flexibility of the purview of the existing regulations in terms of managing the dead in a resilient direction.

As the number of active positive COVID-19 cases in Malaysia has continued to rise since March 2020, the National Institute of Forensic Medicine (IPFN) Malaysia has had to prepare for the worst case scenario of a sudden multiplication in the number of deaths due to COVID-19, which may overwhelm the capacity of the forensic service. In preparation for possible large scale deaths from this pandemic, IPFN Malaysia has improvised procedures and guidelines for management of the dead within the existing regulations in order to achieve a balance between medicolegal requirements and the safety of personnel managing the bodies of the deceased with suspected or confirmed COVID-19 infection.

It is impossible for IPFN Malaysia to work and plan in isolation and thus local collective contributions from various government agencies has been assembled to maximize the capacity to manage the dead based on the prevailing regulations and legislation in the country. In the initial phase, a guideline on management of the dead for all COVID-19 suspected or confirmed deaths within the hospitals as well as from outside the hospitals (brought-in-dead cases by police) is 
produced and sufficient training is delivered not only for the healthcare workers, but also to the first responders who are also at risk when managing the dead due to COVID-19. When mortuaries are overloaded with infectious remains, adopting the concept of a quarantine centre to locate COVID-19 patients if their numbers become overwhelming, there is a need to relocate the remains of all decedents who were infected with COVID-19 to a temporary mortuary centre, known as the COVID-19 Centralized Body Facility.

This paper aims to share Malaysia's strategies for management of the dead in different phases of the COVID-19 pandemic, whereby every opportunity and assistance must be given to suffering families and communities to mourn their loved ones. These steps include allowing next-of-kin the chance for a modified but safe religious or ritual last rites and a dignified temporary controlled burial for unidentified victims. In times of crisis and emergency, the dead can still be managed with the appropriate level of dignity and respect. As part of the core of the humanitarian forensic approach, everyone in the society must be treated without discrimination in relation to the measures put in place to address this COVID19 pandemic, including the proper management of the dead, particularly the unidentified deceased, who should also be treated with dignity and respect.

\section{Conclusion}

Forensic disciplines contributes equally in the combat of COVID-19, integrating law and medicine and working closely with police, funeral directors and other related authorities in managing the dead. Issues with storage and decomposition, shortages of staff and appropriately equipped mortuaries and other crippled resources, can cause bodies to accumulate if they are not managed in a timely manner. Improvised procedures and guidelines for the management of large numbers of decedents have to be put in place to handle the increased volume of bodies. There is a need to integrate sufficient legal complexities into the social context as well as the consideration of the safety of personnel managing the dead during this unprecedented time. It is imperative to plan and take every necessary step during this pandemic for the management of the dead in the country as a basic human right.

\section{Key points}

1. In times of crisis and emergency, the dead can still be managed with the appropriate level of dignity and respect.

2. Management of the dead is flexible where improvised procedures within the structure of the existing regulations can be modified to handle the increased volume of bodies during pandemic.
3. There is no one-size-fits-all approach to the management of the dead.

4. A COVID-19 Centralized Body Facility is a temporary mortuary centre for all COVID-19 deaths within a country.

5. Temporary controlled burial has been adopted as an option that allows the future identification of victims of the pandemic.

Acknowledgements The National Institute of Forensic Medicine (IPFN) Malaysia greatly acknowledges the tremendous support and effort from the Director General of Health and the Director of Hospital Kuala Lumpur throughout the duration of the battle against the COVID-19 pandemic. Special thanks are also extended to the National Disaster Management Agency (NADMA) of the Prime Minister's Department of Malaysia for all the assistance and funding in the COVID-19 related operations. We would also like to express our gratitude towards the medical front liners and all first responders who are directly and indirectly involved in the management of the dead in all COVID-19 cases.

\section{References}

1. Amodio E, Vitale F, Cimino L, Casuccio A, Tramuto F. Outbreak of novel coronavirus (SARS-Cov-2): first evidences from international scientific literature and pending questions. Healthcare. 2020;8(51):1-8.

2. European Centre for Disease Prevention and Control. Considerations related to the safe handling of bodies of deceased persons with suspected or confirmed COVID-19. 2020. https:// www.ecdc.europa.eu/en/publications-data/considerations-relatedsafe-handling-bodies-deceased-persons-suspected-or.

3. Hanley B, Lucas SB, Youd E, Swift B, Osborn M. Autopsy in suspected COVID-19 cases. J Clin Pathol 2020;0:1-4.

4. Kampf G, Todt D, Pfaender S, Steinmann E. Persistence of coronaviruses on inanimate surfaces and their inactivation with biocidal agents. J Hosp Infect. 2012;104:246-51.

5. Finegan O, Fonseca S, Guyomarc'h P, Morcillo Mendez MD, Rodriguez Gonzalez J, Tidball-Binz M, et al. International Committee of the Red Cross (ICRC): general guidance for the management of the dead related to COVID-19. Forensic Sci Int. 2020;2:129-37.

6. World Health Organization. Situation Report-77: Coronavirus disease 2019 (COVID-19). 2020. https://www.who.int/emergencies/ diseases/novel-coronavirus-2019/situation-reports.

7. World Health Organization. Interim guidance: Infection Prevention and Control for the safe management of a dead in the context of COVID-19. 2020. https://apps.who.int/iris/handle/10665/331538.

8. World Health Organization. Report of the WHO-China Joint Mission on Coronavirus Disease 2019 (COVID-19). 2020. https:// www.who.int/news-room/feature-stories/detail/who-china-jointmission-on-coronavirus-disease-2019-(covid-19).

9. National Crisis Preparedness and Response Centre, Disease Control Division, Ministry of Health Malaysia (CPRC). COVID-19 Infographic. 2020. https://www.moh.gov.my/index.php/pages/ view/2264.

10. Nolte KB, Taylor DG, Richmond JY. Biosafety considerations for autopsy. Am J Forensic Med Pathol. 2002;23:107-22.

11. Act 593. Criminal Procedure Code (CPC). Laws of Malaysia. 2012.

12. Act 342. Prevention and Control of Infectious Diseases Act 1988. Laws of Malaysia 2016.

13. Act 344. Police Act 1967. Laws of Malaysia. 2012. 
14. HM Government. Managing the deceased during a pandemic: guidance for planners in England, London. 2020.

15. Malaysia National Security Council (MNSC). Directive 20. 2012. https://www.adrc.asia/management/MYS/Directives_National_ Security_Council.html.

16. Management of dead bodies after disaster: A field manual for first responders. 2nd ed. Washington D.C.: International Committee of the Red Cross; 2016.
17. Mohd Noor MS, Khoo LS, Alias WZZ, Hasmi AH, Ibrahim MA, Mahmood MS. The clandestine multiple graves in Malaysia: the first mass identification operation of human skeletal remains. Forensic Sci Int. 2017;278:410 e1-9.

Publisher's note Springer Nature remains neutral with regard to jurisdictional claims in published maps and institutional affiliations. 